\title{
Empowerment of Small Medium Enterprises through Student Participatory Action Research in Implementation of Accounting Information System
}

\author{
Alexandra Widjaja $^{1, *}$ and Shandy Matitaputty ${ }^{2}$ \\ ${ }^{1}$ Accounting Department, Faculty of Economics and Business, Soegijapranata Catholic University, Jl. \\ Pawiyatan Luhur IV, No.1, Bendan Dhuwur, Tinjomoyo, Banyumanik,, Semarang 50235, Indonesia \\ ${ }^{2}$ Taxation Department, Faculty of Economics and Business, Soegijapranata Catholic University, \\ Semarang 50235, Indonesia
}

\begin{abstract}
Small Medium Enterprises (SMEs) as a vast growing industry are inhibited by its lack of resources, such as capital funding, skill, and technology. It leads to the lack of business information, which is important to be used in decision making process. Accounting Information System (AIS) will enhance their business information's availability and reliability. SMEs need to be supported on designing their AIS. This article aims to propose a learning model in AIS course that could affect both students and community through a project based learning. Project based learning model will enhance, not only student's cognitive ability, but also give them the opportunity to empower their community. This study is expected to help the student becomes both cognitive and affective excellence undergraduate. This study was conducted using a participatory action research which is a collaborative research that equitably involves all partners. The subject of this research is students of Accounting Information System course, Faculty Economics and Business, Soegijapranata Catholic University, Semarang, and the targeted community, which is small medium enterprises in Semarang. This research is conducted through four phases, i.e (i) observation; (ii) Analyzation and Design Planning; (iii) Actuating; and (iv) Evaluation and Monitoring.
\end{abstract}

Key words: Accounting information system, community empowerment, participatory action research, small medium enterprise

\section{Introduction and background}

Small Medium Enterprises (SMEs) are a fast-growing industry, in terms of number. It constitutes large part of private sector in developing countries. SMEs become important for several reasons. It has wide dispersion across rural economies. It also able to employ labor force as it provides an opportunity for entrepreneurial skill to grow [1]. SMEs based on home industry, so usually they have some limited resources. Thus, it has several growth

${ }^{*}$ Corresponding author: alexandra.adriani.w@gmail.com 
constraints, including (i) lack of capital, business information, technology and skilled worker; (ii) difficulties in processing raw materials; (iii) marketing and distribution challenges; and (iv) government policies and regulation [1].

SMEs seldom has financial statement, many of them even does not have an accounting record. SMEs tends not to separate their business capital with owner's fund. It is common to find SMEs which record their sales, but not their procurements. SMEs also tends not including labor cost into their cost-of-good-sold calculation, not to mention the overhead cost. Their nescience toward accounting recording process lead them to a lack-information condition. This condition inhibits their growth, even threaten their business. The absence of accounting information, such as cost of goods sold, gross profit, net profit, etc actually make SMEs unaware of their business's recent condition. It may lead to a false decision making. It also inhibits them to embrace wide opportunity in funding choices, such as government funds or bank loan, because those funding usually eligible for SMEs which could show a reliable financial statement.

Despite of its constraints, there are still opportunity, widely open, for SMEs. Linkage with subcontract or wholesaler could stimulate its technology development [2]. SMEs are also found to be able to respond more quickly and flexible to sudden shock [3]. It is because they are less dependent to formal market or credit. One way to support SMEs is to enhance their accounting skill so they can have accounting information system and generate their own accounting information and financial statement. Nowadays, it's difficult to differ accounting information system with a series of computer software. But, if we look back on its definition, system is defined as a set of two or more interrelated components interacting to achieve a goal [4]. It is clear that in term of definition, system is not identic with a computer software. So, it is very possible to apply an accounting information system in small medium enterprise. Accounting information system could be formed in a series of simple procedures. System development could be formed in a simple document design nor a function separation between its employees.

This article is proposing a combination of learning model, which is a contextual teaching model and project-based learning model. Contextual teaching model is needed to nurture student's knowledge of related topic. Giving them an up to date case study will enhance their theoretical knowledge based on professional world practice. Learning from the best could be a good foundation form them to, later, implement their knowledge through a project-based learning model. Project-based learning model is an innovative learning model, driven by students themselves and facilitated by teacher [5]. Instead of focusing on the teacher, this model is focusing on the learner, encourage them to do indepth analysis toward a certain area [6]. This is also one way to fill the gap between theoretical ability and knowledge-implementation ability.

One way to give them a real-word practice is giving them an opportunity to be an apprentice in a company with a good Enterprise Resource Planning (ERP) implementation. With this internship, the students could see the actualization of ERP implementation with a high-quality standard, but it does not give them a chance to practice designing an accounting information system. The other way is bringing the other side of the spectrum, which is small medium enterprises, which are not only needed help to develop their accounting information system, but also lack of resources. Dealing with small medium enterprise means the student will deal with a smaller scope of system design.

This learning model combination could affect both cognitive and affective ability of undergraduate students. Education should generate holistic graduates, meaning education not only focused on cognitive ability but also enhance their affective towards community. Cognitive-excellent graduates could be successful, but whether they are fruitful could be debatable. Education not only make people smarter, but along with its learning process, education must also enhance humanity. The objective of education is supposedly to give 
back a citizen who could strengthened and empowered to their society. Students have to taught to be an effective and contributive member of society [7]. This article is proposing to use project-based learning model as a service learning project. Students are directed to choose a project with certain criteria. Those criteria are to ensure students can still have the chance to do their comprehensive learning, but the project also should have benefited the community.

Choosing small medium enterprises as a partner will benefited both parties. For students, they will have a chance to practice their cognitive ability along with their other soft skill, such as communication, teamwork, etc. Bring them out of their class and facing them to such a business are expected to give them a different point of view of the society. They will face a business with all its limitation so they will have to adjust their solution according to the business itself. In a wider vision, this program will nurture the student's heart, encouraging them to contribute their skill and knowledge to society. For the small medium enterprises, they will get free assistance to develop their information system. The sustainability of this program will provide them a continuous improvement related to their accounting information system and internal control.

\section{Learning models}

Learning is defined as a process to gain knowledge or understanding of or skill in by study, instruction, or experience [8]. Learning is an active process to gain a new knowledge and modifying or reinforcing an existence knowledge [9]. For undergraduate students, this continuous process usually involves teacher and students in a classroom. The classical method used is teacher-centered learning, where the teacher will give an explanation or some tasks. The room for discussion is limited and students are considered as a receiver [10]. Facing the fast-moving world and technology, we need students who can thinks critically. Critically thinking skills is beyond understanding a knowledge [11]. Teacher not only responsible of student's understanding, but also to teach them think critically. The students must be encouraged to think along the learning process.

Learning systems are needed that encourage divergent reasoning, problem solving, and critical thinking. Student-centered learning environments have been touted as a means to support such processes [12]. Student-centered learning emerged as a learning model focusing on students. There are many teaching techniques as an answer how teacher should be a facilitator in the class. Small group discussion, case study, simulation, and even selfdirected learning could be combined to help students during the learning process. Teacher becomes a facilitator who direct the class according to course's syllabus. Students become the primary actor. They were guided and directed through assignments, discussion or tests to achieve the course's goal. This learning model, focusing on student's participation, ensure their active participation in learning process [13].

Contextual learning enhances their understanding to the next level. This learning model relate theoretical concept with its context in the society [14]. Based on its principles, contextual learning also suitable for Accounting Information System course. With technology moving so fast, topics discussed inside the class should be attached with its context. It could be information technology trends, internal control framework development, and many others. Contextual learning is a bridge between knowledge and its application. Students sometimes understand the basic concept discussed inside the class, but putting it in a real-world context will give students an insight how the knowledge is applied.

Understand the knowledge, and then understand how it can be applied is increasing student's cognitive ability. Up-to-date case study and context widen student's perspectives, still it is different with an experience to actually implement their knowledge. This article is 
proposing project-based learning model to bring their learning process to the next level. Project-based learning is a comprehensive approach to learning. It includes reading, writing, research, and even communication skill. Learning responsibility, independence, and discipline are three outcomes of project-based learning [5]. Students are driven to apply steps they learned in the class to bring out a solution. The solution has to be applicable, it means that they have to consider every possibility and its consequences.

\section{Methodology}

This article uses a participatory action research, which is a collaborative research that equitably involve all partners, i.e student, teacher, and elected small medium enterprise. Participatory action research uses result of research to participate in society's life. Participant do an action through an engagement with experience. Figure 1 showing that participatory action research builds the society by implementing research result in the form of actual action.

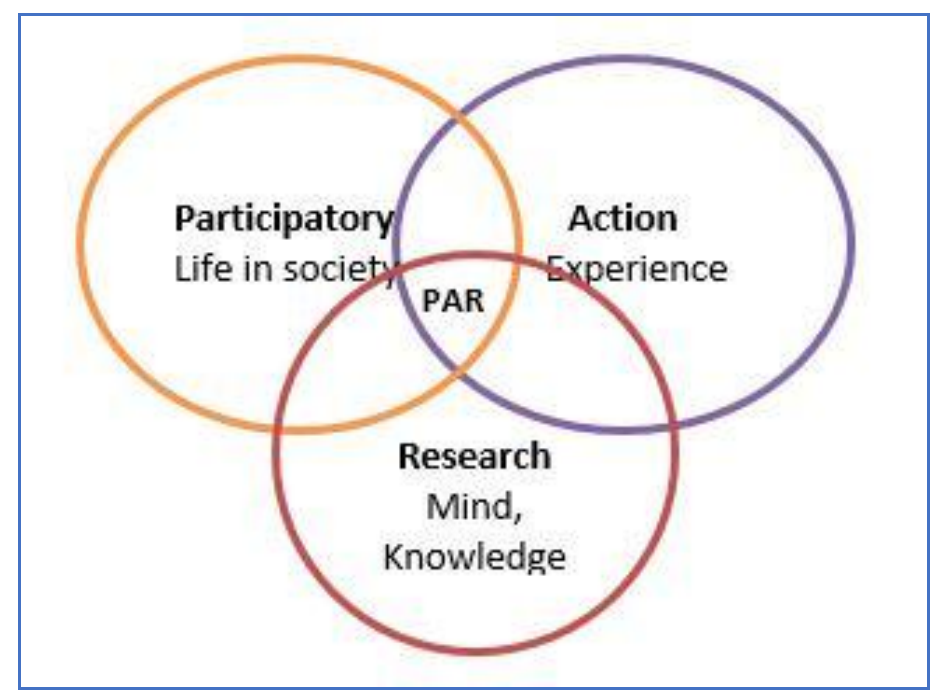

Fig 1. Participatory Action Research [15].

Participatory action research is a qualitative research method. Thus, its purpose is to describe and to understand, rather than to predict and control, a research issue [16]. It is considering people involved as social beings. Consequently, participants recognize as contributors, not just subject, of the research $[16,17]$. The process of participatory action research itself basically is a systematic learning process that involves making critical analyses [17]. This concurrent process establishes self-critical communities, starts with the collaborator of the research itself.

There are various methods used in participatory action research. Collaborators could utilize observation technique, interview, and focus group discussion. This research method is a cyclical process consist of planning, acting, observes, and reflecting [16, 18-20]. These steps are continuously repeated until an issue is solved, just like pictured in Figure 2.

PAR generally has the same pattern as Action Research (AR), both approaches have sequences of planning, action, reflection, and evaluation. In particular, PAR shows participatory and democratic process concerned with developing practical knowing in the pursuit of worthwhile human purposes [20]. The PAR method for education in this article has the same implementation pattern as the PAR method in general. The first phase is 
planning a change; the problems of SMEs and Accounting Information System (AIS) are studied, and then formulated to the preparation of planning through syllabus and lesson plan. The second stage is action, at this stage students observe and understand the business operation cycle, as well as facilitate the choice between available options and guiding the implementation; the last stage is Evaluation and monitoring, demanded all the partners to evaluate the result. This method could be done continuously and also expanded.

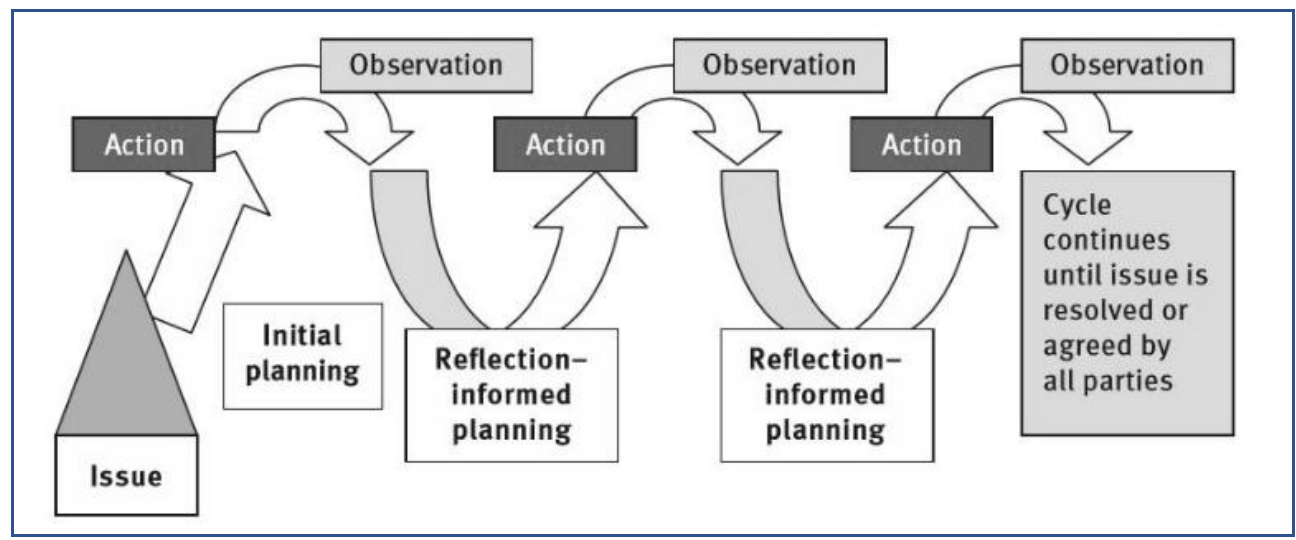

Fig 2. Steps in Participatory Action Research [2].

This cyclical process benefited the collaborators through various ways. In education, PAR can be used to improve the quality of education through improving the quality of learning methods and improving the quality of teachers. PAR creates more specific learning, enriches educational discourse, and serves to improve teacher professionalism [18]. Students enhancing their critical thinking ability during their systematic learning process. Communities also introduced to self-critical process that could encourage growth and improvement. Teachers also improve teaching practice by dealing with complicated society, challenging their performance and professional role [20].

Despite of its advantages, participatory action research has its own challenges. The collaborative process demanding commitment from all collaborator, including community member involved in it. Driven by a different purpose with the other collaborator, students and lecturers, sometimes community members are easily losing their persistence. This method also challenges either students or teacher to manage divergence of perspectives, values and abilities [16]. It also has no set end date, so sometimes it's difficult to determine when an issue is resolved [19].

Students participated in this project are students of Accounting Information System course. This course offered for, at least, second year student. This three credits course usually taken by, approximately, 200 students. They were divided into 25 groups. Each group will visit their partner six times minimum, with lecturers accompanied in two of it. Students are choosing possible SMEs to be their partner. Partner are selected through criteria. First, it has to be categorized as a small-medium enterprise as per Standar Akuntansi Keuangan Entitas Mikro, Kecil dan Menengah (Accounting Standard for Small Medium Enterprises (SMEs)). Second, it has an organization structure consist of owner and employees. Many of the small-medium enterprises are practically runs by its owner only. There is no function differentiation between owner and employees. In those business, there is few possibilities of conflict interest. Internal control urgently needed in an environment where more than one interest emerged. So, it is not ideal for learning an internal control design in a simple organization where the owner is responsible for every practical decision. Two-layer organization structure ensure that student could have a practical experience in 
designing internal control. Partner with two-layer organization usually also has a wider scope of business process and already need more complex information system. Third, partner voluntarily involved and agree to fully participate in this project. Information system implementation is a circular process. It does not end in one cycle only. Evaluation and monitoring are needed after the implementation and any suggestion or development could emerge from the last phase. To maintain this project's benefit, along with its sustainability, partner must agree to fully participate for a long-term and continuous project. Students also have to consider that they are dealing with a real business, so their solution should not delay partner's business process. It is important to make sure that partner could utilize the information system.

Learning outcomes are seen from various aspects, such as the development of students' understanding, the liveliness and enthusiasm of students and SMEs who are accompanied. This means that the success of learning through the PAR method is not only measured by the drastic changes of the accompanying SMEs, but rather the learning process as well as the changing mindset and enthusiasm of all parties involved. The criterion of success is not whether participants have followed the steps faithfully but rather whether they have a strong and authentic sense of development and evolution in their practices, their understandings of their practices, and the situations in which they practice [18].

This learning model will be evaluated by certain criteria. First, student's ability to implement their theoretical knowledge in the real-world practice. It will be evaluated by (i) questionnaire to measure if partner could implement the knowledge shared by student, i.e: current system design, alignment of proposed system design according to partner's need and condition, understandability and easiness if system design implementation. Questionnaire will be filled by partner and lecturer; (ii) assessment form filled by partner and lecturer. Second, student's empathy and concern towards community. It will be evaluated by a questionnaire filled by partner to measure (i) student's ability for listening partner's obstacles or complaint; (ii) student's ability to speak politely and show humility in front of the partner; and (iii) student sincere help toward partner's need to have a good accounting system. Last, student's response toward the implementation of service learning model. Questionnaire will be filled by students to collect their feedback about service learning model.

Evaluation for partner is clearly shown by the progress of this project itself. The preliminary observation generates a preliminary report explaining recent condition of SMEs AIS. The final report of this project clearly shown the difference before and after SMEs joining this participatory action research project.

\section{Practical implementations}

In Accounting Information System course, students will be taught about business process cycle along with its internal control. At the earlier stage of this course, the students are introduced to accounting information system. They overview transaction processing and enterprise resource planning system. They equipped with the ability to document series of procedures using a data flow diagram and flowchart.

The course continued with a knowledge of internal control framework. The first framework introduce to student is internal control framework established by the Committee of Sponsoring Organization (COSO). Internal control-Integrated Framework and Enterprise Risk Management Framework issued by COSO is widely accepted and usually incorporated into policies, rules, and regulations used to control business activities. According to COSOEnterprise Risk Management (COSO-ERM), internal control is a risk-based approach. Begin with objective identification, COSO-ERM identify all risks possible to occur. A risk assessment conducted for each risk to determine its risk response. 
Second framework introduced to students is Control Objectives for Information and Related Technology (COBIT) framework established by Information Systems Audit and Control Association (ISACA). COBIT 5 is a framework for enterprise's IT governance and management. Thus, differ with COSO-ERM, COBIT 5 focusing on IT governance, which has become an integrated part of enterprise's internal control. The COBIT 5 process reference model divides the governance and management processes of enterprise IT into two main process domains, those are governance and management. Management domain contains four domains, in line with the responsibility areas of plan, build, run and monitor (PBRM), and provides end-to-end coverage of IT. Those domains are Align, Plan and Organize (APO); Build, Acquire and Implement (BAI); Deliver, Service and Support (DSS); Monitor, Evaluate and Assess (MEA) [21].

Business process cycle is divided into five modular subjects to simplify student's understanding of enterprise business process, i.e: revenue cycle, expenditure cycle, production cycle, human resources management and payroll cycle, and general ledger and reporting system. On each cycle, student introduce to transaction processing. Their understanding of transaction processing become base of internal control implementation. Students are introduced to, both, internal control implementation based on COSO-ERM and COBIT on each cycle. Then, at the final stage of the course, the students are expected to have a comprehensive knowledge about transaction processing and internal control procedures of business process cycle. This project is conducted through four phases:

\subsection{Observation}

Observation is beginning with understanding partner's business process. Using an interview technique, student gathered a chronological business process. Business process is divided into five modules, which is revenue and cash collection, purchasing and cash disbursement, production, human resource, and general ledger. Observation is conducted on each module. During the interview, students are also collect all supporting document and forms used in the business process. At the end of this phase, students prepare an observation report. This report contains a narrative-descriptive explanation followed by document flowchart. They also enclose all supporting documents and forms.

\subsection{Analyzing and design planning}

Students are having focus group discussion to analyze their findings. Observation data are clustered into five modules, i.e revenue, purchasing, production, human resource and general ledger. Analysis is done by modules, even though all modules are actually related to each other. Students are guided to analyze problems on each module and directly propose solutions. Solutions are formed as a system design.

System design made per module, covering standard operating procedures for each module and its forms and documents. Design process begins with standard operating procedures analysis. Student will use document flowchart as a blue-print of their design. Document flowchart is chosen as a tool because it shows not only the procedures, but also the documents and forms involved in the procedures. It gives a comprehensive view so students can also see the internal control embedded in the procedures. Students are suggested to finish all modules before they describe their design in a form of narrativedescriptive analysis.

While composing their design, teacher have to ensure that the design could be implemented by the partner. Many variables must be considered in the design, especially, regarding the small medium enterprises, human resources and economic resources. Form and document design usually simpler and easy to understand. It should also not too 
expensive and do not add costs as much as possible. Students are encouraged to utilize and optimize partner's resources to avoid capital addition. Students, then, have to explain the new design to the partner. Partner is encouraged to give feedback regarding the proposed design.

\subsection{Actuating}

Once the proposed design is agreed, partners begin to implement the system design. They are suggested to implement the new design by module. Students act as a facilitator during the implementation process. In this phase, students also have to acknowledge any obstacles or difficulties in the implementation process. Students are encouraged to do an immediately action to response those obstacles.

It is very important to remind that this phase is emphasizing student ability to really engage with clients, go side by side with them, during the implementation. SMEs entrepreneur usually comes with a very diverse background. Many of them do not have knowledge nor experience regarding accounting process. Thus, it is very common to find reluctance to change. Some clients may find that accounting is very difficult to understand either or to implement.

Student will learn to overcome these obstacles by training and educating clients, oversee each step of implementation. It will lead them to an immediate response to any reluctance and obstacles during this phase. Teacher has to supervise this phase to guide the student through e real-life system implementation experience. Not only to supervise students, but to relate with partner, ensure their cooperation and satisfaction.

\subsection{Evaluation and monitoring}

This phase started after all modules are implemented. Partners evaluate the new system implemented. Students are also monitor the system implementation followed by submitting their final report to teacher. It is common to, still, report some limitations. However, students are limited by duration of the program. It is also common that there is no single perfect system fit on the first time of implementation. Again, it is, indeed, a cyclical process.

To enhance the sustainability of partnership, if there are any further development possibilities, it will be followed-up by the next round group. Therefore, students are suggested to report obstacles, difficulties and further development possibilities. These reports will be used as a preliminary report for the next group of students. And, therefore, also, important for teacher to maintain a good relationship with the partner. However, teacher is the linkage between student and partner.

Due to the nature of the cycle itself, this last phase is not an end to the partnership. But, it is the last phase for the current group of students. The partnership itself has a tendency to become an endless improvement process. But, along with the process, the partner also improving, and there will be some conditions that it could be considered established in term of Accounting Information System implementation. It is important for teacher to propose those criterions so an end date could be set. Then, the other SMEs has a chance to have the same partnership project. This participatory action research clearly affected the SMEs in their Accounting Information System (AIS). Major changes and development has been made in each module just as summarized in Table 1. 
Table 1. Result Summary.

\begin{tabular}{|c|c|c|}
\hline Module & $\begin{array}{l}\text { Before Participatory Action } \\
\text { Research }\end{array}$ & $\begin{array}{l}\text { After Participatory Action } \\
\text { Research }\end{array}$ \\
\hline $\begin{array}{l}\text { Revenue and } \\
\text { Cash } \\
\text { Collection }\end{array}$ & $\begin{array}{l}\text { - Seldom have sales order documents } \\
\text { - Seldom make organized sales } \\
\text { records }\end{array}$ & $\begin{array}{l}\text { - There are sales order } \\
\text { documents } \\
\text { - There are sales records per day }\end{array}$ \\
\hline $\begin{array}{l}\text { Purchasing } \\
\text { and Cash } \\
\text { Disbursement }\end{array}$ & $\begin{array}{l}\text { - Not able to calculate cost of goods } \\
\text { sold } \\
\text { - Does not collect cash disbursement } \\
\text { document consistently }\end{array}$ & $\begin{array}{l}\text { - Have knowledge about cost-of- } \\
\text { goods-sold calculation } \\
\text { - Organized files of cash } \\
\text { disbursement document }\end{array}$ \\
\hline Module & $\begin{array}{c}\text { Before Participatory Action } \\
\text { Research }\end{array}$ & $\begin{array}{l}\text { After Participatory Action } \\
\text { Research }\end{array}$ \\
\hline Production & $\begin{array}{l}\text { - Does not include labor cost as part } \\
\text { as product cost } \\
\text { - Lack of accounting information as } \\
\text { consideration of business decision } \\
\text { making }\end{array}$ & $\begin{array}{l}\text { - Have knowledge how to } \\
\text { calculate labor cost } \\
\text { - Have accounting information } \\
\text { about cost of goods sold and } \\
\text { profit/loss }\end{array}$ \\
\hline $\begin{array}{l}\text { Human } \\
\text { Resources }\end{array}$ & $\begin{array}{l}\text { - Does not have sufficient AIS } \\
\text { knowledge and skill } \\
\text { - Does not have sufficient } \\
\text { accounting knowledge and skill } \\
\text { - Does not separate between business } \\
\text { and personal financial }\end{array}$ & $\begin{array}{l}\text { - Introduced to accounting } \\
\text { procedures as part of AIS } \\
\text { - Practicing simple accounting } \\
\text { recording process } \\
\text { - Start to separate between } \\
\text { business financial and personal } \\
\text { funds }\end{array}$ \\
\hline $\begin{array}{l}\text { General } \\
\text { Ledger }\end{array}$ & $\begin{array}{l}\text { - Does not have financial statement } \\
\text { - Does not have cost information } \\
\text { regarding fixed and variable cost. }\end{array}$ & $\begin{array}{l}\text { - Could generate simple financial } \\
\text { statement } \\
\text { - Have reliable fixed and } \\
\text { variable cost information }\end{array}$ \\
\hline
\end{tabular}

\section{Conclusion}

This participatory action research shows all parties benefited concurrently as targeted. Student has a real-life experience about observing, analyzing, designing and implementing an Accounting Information System (AIS) design. This is known through student's feedback in the questionnaire during evaluation. Evaluation with partner and lecturer's field monitoring show that (i) Selecting SMEs as partner, ensure that this project does not overwhelm for the student, but at the same time challenge their cognitive, affective, and even their communication skill; (ii) Partner has benefited directly in the form of AIS design. It included forms, document, standard operating procedures, and even reporting, that could support their business operation.

However, this method has its constraints. Commitment of the community could be a challenging factor that endanger this project sustainability. Therefore, it is important to maintain a good relationship with partner, and even better if this project could be institutionalized. Other constraint is the difficulties to set an end date for a partner. Because AIS development is a cyclical process, this project has a tendency to become an endless cycle. Thus, at the beginning of partnership, it is important to have certain benchmarks to indicate that the partner has met certain condition to be considered established, in the term of AIS implementation. Once a partner considered established, the project could target 


\section{References}

1. T.T.H. Tambunan, Journal of Enterprising Communities, 5,1:68-82(2011). https://www.emeraldinsight.com/doi/abs/10.1108/17506201111119626

2. Y. Sato, Bulletin of Indonesian Economic Studies, 36,1:137-166(2000). https://ideas.repec.org/a/taf/bindes/v36y2000i1p137-166.html

3. A. Berry, E. Rodriguez, H. Sandee, Bulletin of Indonesian Economic Studies, 37,3:363-384(2001). https://ideas.repec.org/a/taf/bindes/v37y2001i3p363-384.html

4. M.B. Romney, P.J. Steinbart. Accounting Information System. $13^{\text {th }}$ Edition. United States: Pearson (2015).

5. https://www.pearson.com/us/higher-education/program/Romney-AccountingInformation-Systems-13th-Edition/PGM275950.html

6. S. Bell, The Clearing House, 83,2:39-43(2010). https://www.tandfonline.com/doi/full/10.1080/00098650903505415

7. M.M. Grant, Meridian: A Middle School Computer Technologies Journal, 5:1-17(2002).

https://www.researchgate.net/publication/228908690_Getting a grip on projectbased learning Theory cases and recommendations

8. K.Y.T Lim, M.Y.C. Ong, Citizenship Teaching and Learning, 9,1:71-83(2013). http://www.ingentaconnect.com/contentone/intellect/ctl/2013/00000009/00000001/art 00006

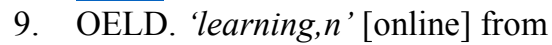
https://en.oxforddictionaries.com/definition/learning (2017). [Accessed on 10 March 2017].

10. P.C. Blumenfeld, E.Soloway, R.W. Marx, J.S Krajcik, M. Guzdial, A. Palincsar, Educational Psychologist, 26,3-4:369-398(1991). https://www.tandfonline.com/doi/abs/10.1080/00461520.1991.9653139

11. R.B. Barr, J. Tagg, Change:The Magazine of Higher Learning, 27,6:12-26(1995). https://www.tandfonline.com/doi/abs/10.1080/00091383.1995.10544672

12. I.W. Sadia, Jurnal Pendidikan Dan Pengajaran Undiksha, 2:219-238(2008). [in Bahasa Indonesia].

http://scholar.google.com/scholar?cluster=7902718990111176467\&hl=en\&oi=scholar $\underline{r}$

13. M.J. Hannafin, S.M. Land, Instructional Science, 25,3:167-202(1997).

https://link.springer.com/article/10.1023/A:1002997414652

14. Froyd, J., Simpson, N. Student-centered learning addressing faculty questions about student centered learning [Online] from http://ccliconference.org/files/2010/03/Froyd_Stu-CenteredLearning.pdf (2010). [Accessed on 5 April 2017].

15. R.G. Berns, P.M. Erickson, The Highlight Zone: Research@work, 5:1-9(2001). https://eric.ed.gov/?id=ED452376

16. J.M. Chevalier \& D.J. Buckles, Participatory Action Research: Theory and Methods for Engaged Inquiry. London: Routledge (2013).

https://www.routledge.com/Participatory-Action-Research-Theory-and-Methods-forEngaged-Inquiry/Chevalier-Buckles/p/book/9780415540322

17. C. McDonald, CJAR, 13,2:34-50(2012). https://journals.nipissingu.ca/index.php/cjar/article/view/37

18. R. McTaggart, 16 tenets of participatory action research, (1989). http://www.caledonia.org.uk/par.htm 
19. S. Kemmis, R. McTaggart, Participatory action research. In: Strategies of Qualitative Inquiry. N.K. Denzin, Y. S. Lincoln (Eds.). Australia: Deakin University (2003). p. 336-396.

http://citeseerx.ist.psu.edu/viewdoc/download?doi=10.1.1.473.4759\&rep=rep1\&type= pdf

20. M. Walter, Social Research Methods. South Melbourne: Oxford University Press (2009). https://catalogue.nla.gov.au/Record/4605474

21. M.P.E. Morales, IJRES, 2,1:156-165(2016).

http://dergipark.gov.tr/ijres/issue/25098/264865

22. ISACA. Information System Audit and Control Association. [Online] from www.isaca.org (2017). [Accessed on October 17 ${ }^{\text {th }}, 2017$ ]. 